\title{
Identifying and Mitigating Maverick Spend
}

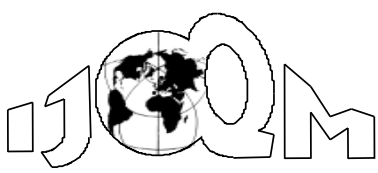

Volume 25, Number 4

December 2019, pp. 219-237
Sureel S. Sheth

Terry P. Harrison

Richard D. Elmore

The Pennsylvania State University

(sss57@psu.edu)

(hbx@psu.edu)

(rde9@psu.edu)

Purchasing Services at the Pennsylvania State University is tasked to support efficient procurement of goods, materials and services across the University. Purchasing Services attempts to capture economies of scale using organization-wide framework agreements, however, this results in various forms of organizational misalignment, which includes purchasing off-contract commonly known as "maverick spend". We describe various research efforts to address the challenges in centralization initiatives and maverick spending. 1) identify proportion of maverick spend, 2) identify root-causes of maverick spending behavior, 3) recommend mitigation strategies to Purchasing Services and 4) provide generalized results for other organizations to assess and mitigate maverick spending.

Keywords: Maverick Spending, Penn State, Off-Contract, Organizational Misbehavior

\section{Introduction}

The Pennsylvania State University (PSU) is a state-related, land-grant University with 24 campuses across Pennsylvania. The University's total enrollment was about 100,000 students across its 24 campuses in the fall of 2017. Because of its scale and geographic distribution, the University has adopted a decentralized purchasing strategy for the purchase of goods and services to support its mission of education, research and service. The Department of Purchasing Services (DPS) at PSU is tasked to support effective and efficient procurement of goods, materials and services across the University, while ensuring compliance to applicable policies, laws and regulations and to maximize utilization of the University's resources and budget. DPS has complete visibility into the spend through catalog, non-catalog and standing orders, however, the it has limited visibility into the spend committed through purchasing cards and special request for checks. DPS speculated that the University may be missing on significant potential savings due to non-compliant purchasing behavior through the decentralized purchasing methods.

DPS attempts to capture economies of scale by augmenting individual purchases with organization-wide framework agreements. Organizations have long realized the importance of consolidating its spend with fewer suppliers to realize cost savings through economies of scale, standardization of purchased products, rebate programs, better purchasing policy and time savings (Cousins et al. 2008). There has been an increasing trend in centralizing purchasing and an organization's strategic planning for supply base reduction (Harland et al. 1999). However, simply establishing 
centralized contractual relationships with key suppliers by itself will not result in benefits or savings without contract compliance (Karjalainen, 2009). Currently, most organizations adopt a hybrid purchasing strategy where supplier selection and contract negotiation is performed by a centralized procurement department, and the purchase of goods/services is decentralized and is performed by various stakeholders of the organization. This approach can lead to different types of non-compliant behaviors in terms of an organization's purchasing policy, which is also known as "maverick spending" (Karjalainen et al. 2009).

Maverick spend can be defined as purchase of goods or services without using the organization's formally defined processes and authorized vendors (Angeles and Nath, 2007). Purchasing goods or services out of contract or from non-preferred suppliers can be detrimental because it impacts profit, contract fulfilment, legal protection, total cost of ownership and supplier relationship (Karjalainen et al. 2009). According to Aberdeen studies, the percentage of compliant transactions is $65 \%$ on average (Aberdeen, 2006a), and maverick buying in services is on average $24 \%$ (Aberdeen, 2003). Lonsdale and Watson (2005), investigating procurement at the National Health Services in UK, found maverick spend to be 50\%, which was broadly set to match the national average. Price water house Coopers calculated that a firm could gain savings of 30-40\% of non-direct spending if they buy only from preferred suppliers (Angeles and Nath, 2007). Also, Kulp et al. (2006) estimated that $20-30 \%$ of unrealized purchasing savings are due to noncompliance. Clearly, maverick spending is a significant problem for many organizations (Karjalainen et al. 2009).

There are various reasons for maverick buying behavior, however there are only a few research studies that identify them. According to Kulp et al. (2006) in their case study of GlaxoSmithKline (GSK), the main reasons for maverick buying include a lack of knowledge about existing framework/contracts, lack of communication of organizational policies to employees, personnel's desire to maintain relationships with unapproved suppliers, lack of specific products in an existing contract and the purchase of new products and/or services not on contract. Cox et al. (2005b) suggested that maverick buying can occur because other functions in an organization are not competent in procurement activities and unaware of the business risks involved. According to Lonsdale and Watson (2005), an informed decision involving functionality-cost tradeoffs may be the reason for maverick buying. Whatever is the reason, the consequences of such buying can be enormous such as those stated by Kulp et al. (2006) in their study of GlaxoSmithKline, who lost $\$ 80$ million - $\$ 120$ million of its potential savings from volume consolidation. They found the key reason to be maverick buying. Academics and practitioners have proposed several means to reduce the extent of maverick buying. However, according to Bartolini (2012)'s findings, on average, half of purchasing spending is non-compliant and even the best-in-class organizations with established e-procurement systems can reach only about $69 \%$ contract compliance. Thus, there is a reason to believe that maverick buying remains a serious issue despite the new technologies (Rothkopf $e t$ al. 2016). 


\section{Literature Review}

A number of researchers have recognized that maverick buying may be encouraged by the hybrid organizational setup of purchasing departments, arguing that the centralization of strategic tasks (i.e., negotiation of organization-wide contracts) and decentralized decisions by the end users on the operational level make firms vulnerable to "organizational misbehavior" (Karjalainen, 2011). In particular, unobservable actions of end users and the fact that most of the consolidation benefits are realized on the central level are seen as joint drivers of non-compliance (Rothkopf et al. 2016). However, to identify the underlying reasons for maverick buying behavior, it is important to understand the motivation of users to commit maverick spend.

In their study of misbehavior in organizations, Vardi and Wiener (1996) identified three categories of organizational "misbehaviors", which are i) misbehaviors intended to benefit oneself, ii) misbehaviors intended to benefit the organization, and iii) misbehaviors intended to inflict damage to the organization. The authors conclude by emphasizing the importance of identifying the form of organizational misbehaviors in order to create effective counter strategies. Karjalainen et al. (2009) extended this study to identify five forms of maverick buying and the reason behind them by performing a systematic literature review of the existing research. According to them the five forms are, i) lack of knowledge about existing frame contract, ii) lack of product availability with existing supplier, iii) lack of incentive to purchase using an existing framework and lack of understanding from a total cost of ownership perspective, iv) lower net price of product / service elsewhere, and v) personal benefits by working with suppliers elsewhere. They validated their hypothesis by interviewing purchasing professionals in the Finnish Government.

Maverick buying may also result from an intent to not relinquish power to the purchasing function, frustration, facilitation of work, boredom/fun and injustice (Ambrose et al., 2002). Establishing centralized contractual relationships with preferred suppliers also requires significant change in organizations, which suggests that maverick buying can be a result of resistance to change. Harris (2002) investigated sabotage in resistance to a market-oriented culture change which could be adapted to give reasons for maverick buying as a form of resistance to change.

In his study of unethical behavior in procurement, Badenhorst (1994) identified five reasons for maverick buying. They include i) the environment of the organization, ii) the role of top management, iii) the existence of limited productive resources, iv) the company culture with regards to its social relations, and v) the intellectual support of the company system. Appelbaum and Shapiro (2006) categorized the types of workplace "deviance" into interpersonal and organizational, and discussed various underlying reasons for deviant behavior. They include unfair treatment, organizational culture, supervisory behavior, greed, theft approval, intent to quit, dissatisfaction with organization, organizational leadership deviance, organizational justice and citizenship behavior, frustration and negative affect. Gelderman et al. (2006) investigated compliance to EU tendering directives in public procurement. They found four reasons for non-compliance which include i) the purchaser's unfamiliarity with the rules, ii) perceived inefficiency of following the rules, iii) lack of organizational incentives and the expected resistance, and iv) readiness of suppliers to take action in case of non-compliance. 
There are several proposed measures to reduce the extent of maverick buying in an organization. Karjalainen et al. (2009) recommends monitoring expenditures in combination with penalties for misconduct, which is commonly known as 'spend analysis'. Studies have shown an improvement in contract compliance due to spend analysis (Minahan and Degnan, 2004).Angels and Nath (2007) proposed eprocurement as a measure to mitigate maverick buying, and discussed challenges in its successful implementation. Croom and Brandon-Jones (2005) discuss the impact of implementing e-procurement system on cost efficiency, form and nature of supplier transaction, IT infrastructure issues and relational impact of e-procurement. They also discussed key challenges faced in implementing e-procurement across a range of UK public sector organizations. Roy (2003) proposed the use of a purchasing card as a permanent payment vehicle to reduce the extent of maverick spend. However, Rothkopf and Pibernik (2016) argued that performing spend analysis and penalizing end users may be ineffective. They proposed participation menus that encourage leveraging end user's purchasing capabilities instead of relying solely on centralized contracts and compliance monitoring. Kulp et al. (2006) in their study of GlaxoSmithKline proposed a three-step approach to tackle noncompliance. These include: i) gathering data, ii) identifying causes of noncompliance, and iii) designing conformance mechanisms. They also discussed the results obtained by aligning control strategies with the supply chain strategy at GlaxoSmithKline.

For this paper we build on prior research addressing noncompliance. Our work is an extension to the work developed by Kulp et al. (2006), however, it differs in that we consider maverick spend in a non-profit, decentralized organization with more than 11,000 authorized end buyers, different methods of purchasing, disparate sources of data, limited resources to perform in-depth spend analysis and universitywide policies. PSU has already adopted purchasing cards (optional) and eprocurement software (eBuy) to facilitate improved spend visibility and leverage. We first incorporated statistical sampling and basic data analysis to identify the proportion of maverick spend in different methods of purchasing. Furthermore, we identified the root-causes of maverick spending behavior at PSU via surveys, conducting interviews and thoroughly reviewing existing policies and procedures. The net effect was to identify large opportunities to reduce maverick buying through the use of a set of diverse mitigation strategies.

\section{Identifying Maverick Spend}

Given PSU's hybrid purchasing strategy, a large number of authorized end users may be able to purchase goods and services. They may choose to use any of the available methods depending on the nature of the purchase, its value and authorized spending limits. There are five methods of purchasing available to end users at PSU. These include eBuy (catalog, non-catalog, standing order), purchasing card and special request for checks (SRFC).

DPS is responsible for monitoring the spend on goods and services across all of the University's campuses. However, the department has limited purchasing authority over several administrative units. We consider the spend through these departments as unaddressable and beyond the scope of this study. The focus of this study is limited to spend by the other administrative units through the methods 
discussed above, and we refer to it as "addressable spend". The first step in the process of devising a mitigation strategy is the identification of maverick spend and its root causes. Next, we discuss our approach to identify the proportion of maverick spend in decentralized purchasing methods and defined methods to identify the largest areas of noncompliance by product categories and administrative areas.

\subsection{Methods of Purchasing}

Since DPS is responsible for monitoring any spend that is committed through the online purchasing portal, eBuy, we identified purchasing card use and special request for check, as 'decentralized' purchasing methods i.e., without any involvement from DPS. We made an assumption that maverick spend, if any, would exist in the decentralized purchasing methods, as the spend committed through eBuy is monitored by DPS.

Any authorized employee at PSU may use a p-card to purchase goods/services, and the payment is completed up front. DPS has no control over this method of buying, which may result in an increased potential for maverick spending.

The SRFC process usually begins when an end user receives an invoice or quote. Most times, the end user receives an invoice as the goods and/or services have already been purchased up front. The end user then submits the invoice to an Administrative Assistant within their department who creates a SRFC. As a minimum requirement, two sets of reviews are performed for any SRFC transaction, which are a budget check and a financial check. Once it is approved by the department, it is sent to Central Accounting or Accounting Operations where the payment is processed for the supplier.

As noted above, payment is processed to the supplier based on a request by the end user, without confirming the actual receipt of goods and/or services, which poses a significant concern. Moreover, an end user usually purchases the good and/or service upfront, which may be an unauthorized purchase through SRFC according to the payment decision matrix. Thus, this method has a potential to promote maverick buying.

After reviewing various methods of purchasing at PSU, it was evident that the spend committed through the decentralized methods of purchasing provide limited spend visibility, and thus, may have a higher probability of promoting maverick spend than centralized methods.

\subsection{Classifying Spend}

In 2017, there were 3,216 end users who purchased at least once through eBuy and there were 4,987 active p-card users for goods and services. It was not possible to determine the number of end users that requested payment through SRFC. However, it is evident that a large number of authorized end users may increase potential of maverick buying. There are 81 administrative areas at PSU that are authorized to approve purchase requisitions for non-catalog orders, standing orders and SRFCs.

SRFC contributes to largest proportion of the total spend at $48 \%$. Together, SRFC and p-card spend make up over $50 \%$ of the total spend and neither of these have direct oversight from DPS. Also, SRFC and p-card make up about $67 \%$ of the total orders. Interestingly, the spend through the internal eBuy catalog is only $3 \%$ of the total spend on goods and services. It is also interesting to observe that non-catalog 
orders comprise of only $3 \%$ of the total number of orders but contribute to $30 \%$ of the total spend. This is due to high spend per orders. Similarly, SRFCs and standing orders have a high spend per order. This explains the reason for a robust approval path for these methods. The focus of this study will be limited to SRFC and p-card spend.

\section{Spend Analysis}

Of the total p-card spend on goods and services at the University in 2017, p-card spend on Amazon Business accounted for about 5\% and contributed to about $10 \%$ of the total number of orders through p-card. Performing a spend analysis of the entire p-card expenditure data was infeasible because of its size, so the p-card spend data on Amazon Business was selected for analysis for three primary reasons. First, the spend data on Amazon Business was recorded in detail. Second, it was relatively easier to compare the availability of products on eBuy (online catalog) versus an eretailer website as opposed to comparing it with in-store purchases. Third, Amazon Business is not a preferred supplier of PSU University and is primarily to be used only for purchase of books and commodities which are unavailable through the online purchasing catalog. Therefore, any purchase through Amazon Business which is not according to the policy may be identified as maverick.

Due to the ease of purchasing through Amazon Business, however, recent purchasing pattern indicates an increase in its use for products available within the eBuy catalog. Since p-card transaction processing is not automated there is a cost associated with every transaction. It also results in a loss of business to the University's contracted suppliers which affects PSU - supplier relationships adversely. In order to identify maverick transactions in the Amazon Business dataset, every item in the transaction had to be checked manually.

Sampling was used to select a subset of transactions from the entire population for all product categories. In the study, 60 transactions were randomly selected from each of ten categories for further analysis.

Table 1 Proportion of Maverick Transactions by Category

\begin{tabular}{|l|c|c|c|c|}
\hline Product Category & $\begin{array}{c}\text { Maverick } \\
\text { Transactions (Out of } \\
\mathbf{6 0})\end{array}$ & $\begin{array}{c}\text { Maverick } \\
\text { Transaction } \\
\text { Percentage }\end{array}$ & $\begin{array}{c}\text { Maverick Spend } \\
\text { Percentage }\end{array}$ & $\begin{array}{c}\text { eBuy Premium } \\
\text { over Amazon }\end{array}$ \\
\hline Personal Computer & 46 & $77 \%$ & $64 \%$ & $103 \%$ \\
\hline Office Product & 53 & $88 \%$ & $93 \%$ & $162 \%$ \\
\hline $\begin{array}{l}\text { Business, Industrial, \& } \\
\text { Scientific Supplies }\end{array}$ & 51 & $85 \%$ & $77 \%$ & $105 \%$ \\
\hline Home Improvement & 41 & $68 \%$ & $71 \%$ & $173 \%$ \\
\hline Consumer Electronics & 48 & $80 \%$ & $72 \%$ & $170 \%$ \\
\hline PC Accessory & 29 & $48 \%$ & $32 \%$ & $148 \%$ \\
\hline Speakers & 52 & $87 \%$ & $70 \%$ & $76 \%$ \\
\hline Photography & 20 & $33 \%$ & $21 \%$ & $102 \%$ \\
\hline Home & 43 & $72 \%$ & $77 \%$ & $142 \%$ \\
\hline Kitchen & 32 & $53 \%$ & $55 \%$ & $109 \%$ \\
\hline Total & $\mathbf{4 1 5}$ & $\mathbf{6 9 \%}$ & $\mathbf{5 9 \%}$ & $\mathbf{1 2 7 \%}$ \\
\hline
\end{tabular}


Table 1 shows the total number of maverick transactions for each category when compared with items available in the eBuy catalog. Most of the categories have a significant proportion of maverick transactions. On average, the total proportion of maverick transactions for the top ten categories is about $69 \%$. The price of all maverick items in Amazon Business was compared with the same item price on the eBuy catalog. It is interesting to observe that PSU is paying a premium of $27 \%$ on the net price of items on the eBuy catalog as compared to Amazon Business. This spend however, does not include the cost of shipping and processing transactions through both methods.

As found by Chaudhary (2018), the cost to process a p-card transaction was found to be between $\$ 10.20$ - $\$ 21.10$. In his study, he also performed a sensitivity analysis of total spend on Amazon Business, by taking different values of transaction processing cost. He determined that the maverick spend committed on Amazon Business by end users, did not incur additional cost to the University, even after incorporating the cost of processing a transaction. However, other costs include longer cycle time, cost of installing standard software and specifications of PCs as required by the University, cost of extended warranties, etc.

From the discussion above, three critical insights can be derived for the expenditure on Amazon Business. They are

- On average, about $69 \%$ of the transactions for top 10 categories on Amazon Business are maverick

- On average about $59 \%$ of the total spend for top 10 categories on Amazon Business is maverick

- On average, PSU is paying a premium of $27 \%$ on the net price of items on catalog, as compared to Amazon Business for the top 10 product categories. The spend through the SRFC method in calendar year 2017 contributes to the largest proportion of the total spend at PSU among different methods of purchasing. In order to identify the proportion of maverick spend, a spend analysis was performed on the SRFC expenditure data for calendar year 2017. It was found that a significant amount of spend went through SRFC and was unauthorized.

Table 2 shows the trend of spend through different methods of purchasing over the last seven years. The spend through eBuy consists of catalog, non-catalog and standing orders. Due to the implementation of the eBuy catalog in 2012-13, and the overall increase in the University budget, there is an increase in overall spend through eBuy. It is interesting to observe that the number of transactions and total spend through p-card remained relatively constant over the years. However, the total spend and transactions through SRFC have increased dramatically in the last seven years. It was also interesting to observe that the total spend through SRFC was less than the total spend through eBuy by about $24 \%$ in 2011 , whereas it surpassed the total spend through eBuy by about $2 \%$ in 2017 .

Using the payment decision matrix as a basis, two subsets of data were extracted from the original dataset. The expenditure data of SRFC was analyzed and a subset corresponding to these object codes was extracted, which was called 'Maverick Spend'. This dataset contributed to $9.1 \%$ of the total transactions and $5.3 \%$ of the total spend through SRFCs at PSU. 
Table 2 Year over Year Growth in Spend and Transactions through Purchasing Methods

\begin{tabular}{|c|c|c|c|c|c|c|}
\hline \multirow{2}{*}{ Year } & \multicolumn{2}{|c|}{ SRFC } & \multicolumn{2}{c|}{ P-Card } & \multicolumn{2}{c|}{ eBuy } \\
\cline { 2 - 7 } & $\begin{array}{c}\text { YOY } \\
\text { Growth In } \\
\text { Spend (\$) }\end{array}$ & $\begin{array}{c}\text { YOY Growth } \\
\text { In Transactions }\end{array}$ & $\begin{array}{c}\text { YOY } \\
\text { Growth In } \\
\text { Spend (\$) }\end{array}$ & $\begin{array}{c}\text { YOY Growth } \\
\text { In Transactions }\end{array}$ & $\begin{array}{c}\text { YOY } \\
\text { Growth In } \\
\text { Spend (\$) }\end{array}$ & $\begin{array}{c}\text { YOY Growth } \\
\text { In Transactions }\end{array}$ \\
\hline 2012 & $26.14 \%$ & $2.72 \%$ & $2.34 \%$ & $-0.06 \%$ & $-1.20 \%$ & $-6.14 \%$ \\
\hline 2013 & $2.00 \%$ & $2.51 \%$ & $-2.07 \%$ & $-1.92 \%$ & $8.51 \%$ & $-0.94 \%$ \\
\hline 2014 & $2.29 \%$ & $7.12 \%$ & $-0.37 \%$ & $-2.12 \%$ & $11.05 \%$ & $0.79 \%$ \\
\hline 2015 & $13.16 \%$ & $15.28 \%$ & $-0.30 \%$ & $4.68 \%$ & $-1.79 \%$ & $0.29 \%$ \\
\hline 2016 & $1.96 \%$ & $4.42 \%$ & $-2.09 \%$ & $-4.27 \%$ & $-2.78 \%$ & $-1.23 \%$ \\
\hline 2017 & $7.16 \%$ & $-2.25 \%$ & $5.17 \%$ & $1.68 \%$ & $7.66 \%$ & $1.90 \%$ \\
\hline $\begin{array}{l}\text { Cumulative } \\
2011-2017\end{array}$ & $62.72 \%$ & $32.72 \%$ & $2.50 \%$ & $-2.23 \%$ & $22.38 \%$ & $-5.40 \%$ \\
\hline
\end{tabular}

As defined in the payment decision matrix, certain object codes have restricted authorization in the use of SRFC as a method of payment. All transactions that violated this policy were extracted in a table called 'Potential Maverick Spend'. This dataset consisted of roughly $0.9 \%$ of total transactions and contributed to about $11 \%$ of the total spend through SRFCs. Since the dataset contained relatively fewer transactions, but contributed to a significant amount of spend, this dataset was analyzed in greater detail. The explanations provided by end users for these transactions were reviewed manually and with the assistance of purchasing experts, the transactions were categorized as maverick or non-maverick. The final potential maverick spend dataset contained $0.5 \%$ of the total transactions and contributed to $6.8 \%$ of the total spend through SRFCs.

Initially, maverick spend was categorized by administrative areas to analyze spend distribution. Of the total 71 administrative areas that committed maverick spend, 14 contributed to about $83.6 \%$ of the total spend. Similarly, the potential maverick spend data was reviewed by administrative areas to analyze spend trends. Of the total 47 administrative areas that committed potential maverick spend, 14 administrative areas contributed to about $82.7 \%$ of the total spend. There are only five administrative areas which are common in both.

The focus should be on administrative areas which exhibit a high degree of noncompliant behavior. For this reason, 'Total Maverick Spend' was calculated by taking the sum of both maverick spend and potential maverick spend for each administrative area. Then the proportion of total maverick spend was calculated as a percentage of total spend through SRFC for each administrative area. Administrative areas were subsequently ranked based on the value of total maverick spend and its proportion. A total of 15 out of 71 administrative areas contributed to $72 \%$ of the total maverick spend.

In order to develop a mitigation strategy, identifying top administrative offices that commit maverick spending is insufficient. According to the Aberdeen Group study (2004), as much as $30 \%$ of all the spending data are incorrectly categorized or classified as "miscellaneous" across all the industries, due to insufficient commodity expertise, which further complicates efforts to analyze and leverage spending. In our 
case, only about $2 \%$ of the total spend through SRFCs is classified as miscellaneous. However, about $63.5 \%$ of the spend data in the maverick dataset is classified as miscellaneous, which makes it challenging to further analyze it. A significant amount of unauthorized spend was pursued in non-capital software or license agreements. Since the use of any software may expose PSU to the risk of proprietary loss of confidential information, any software must be approved by the Office of Information Security before its purchase.

An interesting observation was made in that the average spend per transaction for non-computer equipment purchases, is over $\$ 15,000$, whereas SRFCs should generally be used for transactions smaller than $\$ 10,000$ in value.

We observed that there is significant spend in product categories such as noncomputer equipment purchases under $\$ 5,000$, laboratory supplies and office supplies, which are available through eBuy. This prevents PSU from achieving spend leverage with its contracted suppliers. A significant dollar amount is spent on printing and copying, in spite of having a contracted supplier of the University.

Similarly, the potential spend data was distributed by object codes to identify top spend product categories. Purchased services and awards to employees, and personal/ professional services contribute to about $80 \%$ of the total potential maverick spend through SRFC. It was identified that the biggest reasons for noncompliant purchasing in these two categories were in an attempt to avoid the preestablished approval path for convenience. Similarly, a significant unauthorized spend was identified in construction, which is included in the category maintenance outside vendors.

Each SRFC is entered into the internal system manually before it is sent to Central Accounting/ Accounting Operations for final processing. Because SRFCs are entered manually, there is a high probability of duplication of vendor names in the system. For instance, Amazon, amazon.com and Amazon Business, are all recorded as different vendors. This phenomenon was experienced for several vendors in the expenditure data. Due to this reason, it is difficult to gain clear spend visibility to discover potential new suppliers for long term partnership. This problem is not only limited to maverick spend and potential maverick spend datasets, but also the entire SRFC expenditure dataset.

From the above discussion, the following critical insights can be derived,

- From 2011 - 2017, spend through SRFCs has increased by more than $62 \%$ and SRFC transactions have increased by more than $32 \%$.

- About $12 \%$ of the total addressable spend through SRFC in 2017, was maverick

- The phenomenon of maverick spend through SRFC was identified across the University

- About $3.4 \%$ of total addressable spend through SRFC, was classified as miscellaneous

- Unauthorized spend in certain categories such as non-capital software and travel, may create the risk of proprietary information loss and liabilities

\section{Reasons for Maverick Buying}

The systematic review conducted to understand purchasing methods in detail lead to identification of different forms of potential maverick buying and their attendant root-causes. In an effort to further understand the root-causes of maverick buying, a 
series of interviews were scheduled with purchasing professionals, internal audit, financial officers, reconcilers and professionals involved in the payment processing.

The interviews were semi structured which allowed natural interaction and provided interesting comments in addition to fulfilling the original purpose of the study. Two of the interviewees were representatives from DPS, one from internal audit, one from central accounting, one from the corporate controllers' office and four from units involved in purchasing through these methods. The average duration for all interviews was approximately one hour.

The most common reason identified for maverick spend through SRFCs was found to be confirming orders. According to one of the senior purchasing professionals, most end users approach their department with an invoice against the purchase of goods and/or services. Since the goods/services have already been purchased before prior approval, most departments choose to approve the SRFC for the payment, while warning the end user for non-compliant behavior. Moreover, since DPS does not currently process purchase orders for confirming orders, the users may be compelled to use an SRFC. This further motivates the end user to commit maverick spend and bypass the pre-established processes of purchasing. Since there is no department which is designated to have oversight of all payments made through SRFC, and the task is decentralized to individual administrative areas, there is an increased tendency for such non-compliant behavior.

The interviewees also mentioned several situations in which end users were unaware of the eBuy catalog program. Several interviewees explained that since eBuy has a difficult user interface, end users prefer to use Amazon or other eretailers instead of eBuy. However, from the summary of survey results it was evident that only $25 \%$ of the respondents had received formal training in eBuy, which explains the reason above. Another reason provided was that only a few users in any given office are trained in using eBuy, and if they are unavailable due to any reason, the other end users have to rely on p-cards for purchase. This may be a case of forced maverick spending.

The existing policy on the use of Amazon Business does not mandate the use of the eBuy catalog for available items. In fact, it promotes the use of Amazon Business for categories other than office supplies, laboratory supplies and janitorial supplies. This fact is also supported by the p-card spend analysis, where about $69 \%$ of the transactions for top 10 categories on Amazon Business were maverick. Similarly, during one of the interviews it was discovered that currently there is no clear policy defined for the use of SRFC as a method of payment at PSU. Thus, any end user may not be held accountable for violation of the payment decision matrix, as no sanctions are defined for SRFC misuse.

\subsection{Surveys}

DPS sends out a survey regularly to the end users to understand and improve existing purchasing practices. In an attempt to understand the reasons for off-contract spending at the University, DPS designed and sent out a survey to approximately 11,400 end users across the University. These end users included eBuy users and pcard holders. The total response received was approximately 1,300, making the response rate $11.4 \%$. The survey had 11 questions of which one question was scale based, and one question was open field, and 9 questions were multiple choice. 
According to the survey results, of the total number of respondents more that $77 \%$ of end users were aware of preferred suppliers or volume discounts through eBuy catalog purchasing. However, interestingly, only $25 \%$ of the total respondents had received formal training in eBuy catalog purchasing. This may be due to the lack of incentive for end users to purchase through eBuy catalog, or due to the lack of interest from upper management in understanding the benefits of using preferred suppliers and promoting the same within the organization. Of the total respondents, more than $80 \%$ responded positively that they had read and understood the University purchasing policy. Thus, DPS may focus on other mitigation strategies, such as better compliance monitoring for effective results.

The next set of questions in the survey were focused on analyzing the perception of end users towards user-friendliness of the eBuy catalog. The question addressed the ease / difficulty of finding an item on the eBuy catalog, and it was a scale-based question from 1 being easiest to 10 being most difficult. The mean of responses was 5.17. Another question asked the users whether they would prefer to use the eBuy catalog if its interface was more user friendly. More than $52 \%$ of the responses were positive, whereas about $44 \%$ of the responses were neutral. Only about $3.7 \%$ of the total responses were negative. The above result is consistent with the prior result and it supports that over half of the respondents find eBuy catalog to be more complex than e-retailers.

The next set of questions in the survey asked the respondents whether they checked for the availability of an item on eBuy catalog before purchasing it using their p-card. About $47 \%$ of the respondents looked for an item in the eBuy catalog before purchasing elsewhere, and about $27 \%$ respondents looked for an item on the eBuy catalog only sometimes. This result was found to be a bit inconsistent, in that about $75 \%$ of the respondents did not receive formal training in eBuy catalog. To follow up, users were asked whether the net price of items available through eBuy catalog were higher than other e-retailer websites or in-store purchases. About $19 \%$ of the respondents argued that the prices were usually higher in the catalog, and about $59 \%$ of the respondents agreed that prices were higher sometimes. This fact supports our analysis of p-card spend on Amazon Business where the net price of items on the eBuy catalog was found to be higher by about $27 \%$ as compared to Amazon Business across the top ten categories.

The next set of questions in the survey was aimed at identifying reasons for the use of a p-card. The users were asked about their preferred method of purchasing for small-dollar value items. It was not surprising to find that about $53 \%$ of the respondents preferred a p-card over the eBuy catalog. This result was consistent with above findings as $75 \%$ of the users did not receive formal training and about $52 \%$ of the users would adopt the eBuy catalog if it was more user friendly. Another question asked about the situations under which they purchased using a p-card instead of the eBuy catalog. About $30 \%$ of the respondents preferred to use a p-card when an item was unavailable in the eBuy catalog, making it the most preferred situation. About $26 \%$ of the respondents preferred to use a p-card when a cheaper option was available elsewhere. However, users do not analyze the purchase from a total cost of ownership perspective and compare items solely on the basis of net price. About $22 \%$ of the respondents agreed that they preferred to purchase using a p-card because better option / variety was available elsewhere. Approximately 13\% 
of the respondents used a p-card because of complexity in using the eBuy catalog. Interestingly, about $5 \%$ of the respondents did not have budget preauthorization to purchase through the catalog.

Finally, the end users were asked which method of purchasing was least expensive to process, according to their knowledge. The results were consistent as out of the total number of respondents about $64 \%$ believed that processing the eBuy catalog purchases was the least expensive, $25 \%$ believed that processing p-card transactions was the least expensive, $6 \%$ believed that processing standing orders was least expensive, $3 \%$ believed that processing non-catalog / purchase order was least expensive and only $2 \%$ believed that processing SRFCs was the least expensive.

\subsection{Root-Causes of Maverick Spend}

For maverick spend through a p-card or SRFC, the following were identified as root causes,

- Lack of a clear policy which defines authorized use of SRFC as a method of payment

- Lack of departmental oversight on spend through SRFC

- Lack of a corrective action in case of confirming orders

- Lack of knowledge in using preferred suppliers / volume discounts

- Absence of a policy that mandates purchase of items through eBuy when possible

- Absence of a mandatory eBuy and SRFC trainings for end users involved in purchasing

- Lack of an incentive for end users in using preferred suppliers

- Number of University wide p-card holders

- Lack of supplier performance and price monitoring

\section{Mitigation Strategies}

After performing the various analyses, the following mitigation strategies are recommended for the short-term, medium-term and long-term phases.

The existing policy on the use of a PSU p-card does not require an end user to purchase items through the eBuy catalog even if they are available. The end users may purchase items from off-contract suppliers which may not enable PSU to achieve spend leverage and volume discounts with contracted suppliers. Moreover, Amazon Business guidelines promote the use of Amazon Business for better business pricing. Thus, the end users may not be held accountable for committing maverick spend if they purchase off-contract. The spend analysis of p-card expenditure on Amazon Business attests the fact that 59\% of the spend on Amazon Business in 2017 was maverick. Similarly, there is no clear policy defined for payments made through SRFC. End users are encouraged to use the payment decision matrix as a basis to determine the method of purchasing but are not required to use it. About $12 \%$ of the total addressable spend through SRFC in 2017 was maverick. The end users may not be held accountable for unauthorized purchases through SRFC, due to the lack of a policy.

Therefore, the University should modify the existing policy defined for the use of PSU p-card to mandate the use of the eBuy catalog for available items. The University should also create a new policy which defines the approved use of an 
SRFC as a method of purchasing, as well as clearly defining an approval path for an SRFC transaction. The policy should also include sanctions for misuse of an SRFC and confirming orders. Since SRFC is the largest method of payment for goods and services, it is highly imperative to establish a policy and monitor payment through this method to ensure compliance, and leverage spend capability.

End users are required to undergo online training and take an online test before obtaining a p-card. However, end users are not required to undergo eBuy or SRFC training. Looking at the spend distribution by various methods, it is evident that the spend through p-cards was only $6 \%$ of the total spend for goods and services in 2017, whereas the spend through eBuy and SRFC combined was about $94 \%$ of the total spend. This signifies the importance of end user training. Moreover, it is evident that more than $50 \%$ of the respondents believed that the eBuy catalog is more complex as compared with other e-retailers. However, only $25 \%$ of the respondents had received a formal training in eBuy. With DPS looking to grow the eBuy catalog program by including new suppliers to the catalog, it is highly imperative that the end users are trained in purchasing through eBuy. Similarly, as SRFC is the largest method of payment for goods and services at PSU, it is important to train end users in using SRFCs.

Table 3 Best Practices for Spend Analysis (Aberdeen, 2004)

\begin{tabular}{|c|l|}
\hline No. & \multicolumn{1}{|c|}{ Spending Analysis Practice } \\
\hline 1 & Audit existing spend data management capabilities \\
\hline 2 & Access all spend data sources within and outside the organization \\
\hline 3 & Adopt a common classification schema organization-wide \\
\hline 4 & $\begin{array}{l}\text { Establish efficient and repeatable data cleansing and classification capabilities through } \\
\text { the use of software or services }\end{array}$ \\
\hline 5 & Augment category expertise to ensure data and classification accuracy and validation \\
\hline 6 & Classify spending at a detailed level \\
\hline 7 & Enhance core spend data with vital business intelligence \\
\hline 8 & Increase frequency and coverage of spending analyses \\
\hline 9 & Utilize advanced reporting and decision support tools \\
\hline 10 & Continuously expand uses and scope of spend data management program \\
\hline
\end{tabular}

The spend through the eBuy catalog in 2017 was only $3 \%$ of the total spend on goods and services. This is an extremely small portion of the total spend, which may be attributable to the fact that the University has only 30 contracted suppliers. DPS should regularly perform spend analysis for the entire expenditure data to identify top spend item categories, top spend departments and top spend suppliers to facilitate identification of savings opportunities through aggregation and volume discounts.

According to Aberdeen (2004), the success of any supply management program is largely dependent on its ability to access, organize and analyze its spend data. Based on their study, they found ten best practices for spending analysis which are listed in Table 3. 


\subsection{Change Management}

One of the biggest factors that may influence non-compliant behavior in purchasing is organizational culture and the role of top management. Since PSU has more than 10,000 authorized end users across university-wide purchasing, it is critical to involve senior management in the strategy development for any new process or procedure during the early stages.

DPS must communicate the benefits of using preferred suppliers and adherence to purchasing policies to the senior management at PSU. These benefits include not only tangible benefits such as cost savings, time savings spend leverage and volume rebates, but also intangible benefits such as improved buyer-supplier relationships, protection from liabilities, information security and better service.

The use of $\mathrm{p}$-cards is currently limited to small dollar value items, typically less than $\$ 2,000$, and which may not available through the eBuy catalog. A policy defines guidelines for the use of p-card as a method of purchasing. However, recent advances in technology have enabled improved integration of $\mathrm{p}$-card data with other purchasing methods and has thus received a wide adoption from universities across the U.S. for more than just off-contract and small dollar-value purchases. According to a report by JP Morgan (2007), there has been a significant increase in the use of pcards as a permanent payment vehicle at many universities. According to Aberdeen's (2005) study, the biggest hindrance in wide acceptance of the p-cards is the fear of fraudulent activities. However recent technological advancements allow integration of p-card with General Ledger (GL), Enterprise Resource Planning (ERP) systems, and e-procurement systems and thus provide a high level of spend visibility, which facilitates detailed spending analysis. Roy (2003) discusses the concepts of basic knowledge of p-card use and working knowledge of p-card use, and how they can be leveraged to increase use of p-card purchase for approved suppliers. Based on academic research and current practices at PSU, the following strategies are recommended,

- Improve Integration of P-Card Spend Data - According to the Aberdeen Group (2004), best in class organizations are reconciling p-card transactions online. An electronic card management system is integrated into the organization's general ledger, thereby allowing accounting entries for card transaction to be automatically fed into the enterprise-wide financial reporting system. Currently p-card transactions are reconciled manually, which involves significant effort and creates an opportunity for errors in data. However, reconciling p-card activities via electronic workflows enables collection of data, which can further increase spend reduction by $1.3 \%$ - 5.5\% via sourcing and compliance effectiveness (Aberdeen, 2005). It will also result in gaining better spend leverage and financial reporting.

- Purchases under Master Agreement - Currently p-cards are used only for incidental, unplanned or undefined purchasing transactions. However, Aberdeen (2005) recommends using p-cards as a permanent payment vehicle as an alternative to an e-procurement system with approved suppliers to reduce transaction and process costs via an electronics payment approach. Some end users have difficulty using online catalogs and thus are encouraged to commit maverick spend through other methods of purchasing. This approach has benefit as it promotes such end users to purchase from approved suppliers. 
- Establish Effective Monitoring - It is extremely important to monitor the activities of p-cards and establish control to successfully run a p-card program. Reconcilers and Internal Audit at PSU are responsible for monitoring the activities of buyers through all methods of purchasing and take corrective action or inform the responsible personnel in the event of non-compliance. DPS should organize formal training for reconcilers to improve spend monitoring.

- Extend the use of P-Cards to Purchase orders and other Categories Traditionally, p-cards have been used for purchasing certain categories such as office supplies, computer equipment, MRO supplies, etc. However, recent studies indicate that $\mathrm{p}$-cards may also be used for non-traditional service categories such as advertising, marketing, print, maintenance, temporary services and consulting. This paradigm shift is backed by a clear intent to reduce paperwork to the largest extent possible. It is also recommended to use p-cards for purchases that originated from small dollar value purchase orders in order to improve efficiency.

- Mandate P-Card user Training -The basic knowledge of p-card entails familiarity with p-cards and how to use it along with other methods of purchasing. Currently at PSU, an end user is required to complete online training followed by an online quiz to qualify for obtaining a p-card. However, a working knowledge entails gaining detailed knowledge of p-card which can be obtained only after its actual usage. During this stage, it is important to educate end users of the organizational benefits associated with compliant usage of $\mathrm{p}$ cards, which include long term buyer-supplier relationships, clearer accounting and reporting, improved spend visibility and better spend leverage.

- Involvement from Senior Management - It is important to understand the benefits of having a p-card program which eliminates paper checks and invoices thereby decreasing cost and time for the University. These benefits must be demonstrated to higher management for successful growth of the p-card program at PSU.

Currently, PSU does not have a designated department that is responsible for monitoring the spend through SRFCs. This partially explains the reason for the significant growth in the spend through SRFCs over the last seven years. As stated by Karjalainen (2011), compliance monitoring is extremely important to realize the benefits of negotiated contracts or established policies. Compliance monitoring also ensures protection of an organization against legal liabilities and efficient use of resources.

The action plan described in Table 4 is developed for DPS based on the preceding discussion.

\section{Future Work}

This study is based on the work of previous scholarly research on how to identify non-compliant behavior in purchasing, also known as maverick buying, and to provide solutions to mitigate the same. In doing so, a structured approach was used to review different methods of purchasing. The methods which did not provide a clear visibility into the process were identified and studied in greater detail to understand the approval flow of transactions through those methods. After gaining a 
detailed understanding of the methods, the proportion of maverick spend in each method was estimated using quantitative analysis. A root-cause analysis was performed by using various means such as surveys, meetings, discussions, reviews of policies and current practices at the University. Finally, mitigation strategies were recommended for the short-term, medium-term and long-term phases to mitigate or eliminate maverick buying. This study establishes a basis for future work which can further assist the University and others in achieving a streamlined operation and an efficient use of its resources. Future work may be focused on analyzing the potential savings lost due to insufficient volume consolidation with preferred suppliers or due to maverick buying at PSU. The study may be extended by calculating the transaction processing cost for various methods of purchasing and identifying the best method of purchasing for different product/service categories. Future work may also be focused on performing spend analysis to identify new potential suppliers for long-term partnership, tracking performance of existing preferred suppliers to monitor compliance and tracking end users purchasing history to identify different groups of users based on maverick buying behaviors.

Table 4 Action Plan for Mitigating Maverick Spend

\begin{tabular}{|c|c|c|c|}
\hline Time Phase & $\begin{array}{c}\text { Mitigation } \\
\text { Strategy }\end{array}$ & Current Practice & Future Recommendation \\
\hline \multirow{2}{*}{$\begin{array}{l}\text { Short-term } \\
(0-6 \\
\text { months })\end{array}$} & $\begin{array}{l}\text { Change in } \\
\text { Policy }\end{array}$ & $\begin{array}{l}\text { - eBuy Catalog not mandated } \\
\text { - No clear policy for SRFC use }\end{array}$ & $\begin{array}{l}\text { - Mandate use of the eBuy catalog for } \\
\text { available items } \\
\text { - Establish new policy for SRFC use }\end{array}$ \\
\hline & $\begin{array}{l}\text { End User } \\
\text { Training }\end{array}$ & $\begin{array}{l}\text { - Voluntary eBuy training } \\
\text { - No SRFC training }\end{array}$ & $\begin{array}{l}\text { - Mandate eBuy training for p-card } \\
\text { holders } \\
\text { - Mandate SRFC training for SRFC users }\end{array}$ \\
\hline \multirow{2}{*}{$\begin{array}{l}\text { Medium- } \\
\text { term } \\
(6 \text { months - } \\
2 \text { years })\end{array}$} & Spend Analysis & $\begin{array}{l}\text { - Spend analysis performed } \\
\text { irregularly } \\
\text { - Only performed for spend } \\
\text { through eBuy }\end{array}$ & $\begin{array}{l}\text { - Perform regular spend analysis of the } \\
\text { entire expenditure data for goods and } \\
\text { services } \\
\text { - Adopt data visualization software to } \\
\text { facilitate spend analysis }\end{array}$ \\
\hline & $\begin{array}{l}\text { Change } \\
\text { Management }\end{array}$ & $\begin{array}{l}\text { - No involvement of senior } \\
\text { management in change } \\
\text { management }\end{array}$ & $\begin{array}{l}\text { - Involve senior management in new } \\
\text { policy implementation for effective } \\
\text { results }\end{array}$ \\
\hline \multirow[b]{2}{*}{$\begin{array}{l}\text { Long-term } \\
\text { (beyond } 2 \\
\text { years) }\end{array}$} & $\begin{array}{l}\text { P-card Program } \\
\text { Growth }\end{array}$ & $\begin{array}{l}\text { - P-card use limited to off- } \\
\text { contract purchase } \\
\text { - Manual reconciliation }\end{array}$ & $\begin{array}{l}\text { - Adopt p-card as permanent payment } \\
\text { vehicle } \\
\text { - Incorporate electronic reconciliation }\end{array}$ \\
\hline & $\begin{array}{l}\text { Compliance } \\
\text { Monitoring }\end{array}$ & $\begin{array}{l}\text { - No designated department to } \\
\text { monitor spend through } \\
\text { SRFCs } \\
\text { - Incomplete monitoring of } \\
\text { spend through p-card }\end{array}$ & $\begin{array}{l}\text { - Designate an office / department to } \\
\text { monitor spend through SRFCs } \\
\text { - Complete monitoring of p-card spend } \\
\text { using electronic reconciliation }\end{array}$ \\
\hline
\end{tabular}

\section{References}

1. Aberdeen Group (2006a), The Contract Management Benchmark Report Procurement Contracts - Maximizing Compliance and Supply Performance. Boston, MA: Aberdeen Group.

2. Aberdeen Group (2006b), The E-Procurement Benchmark Report. Boston, MA: Aberdeen Group. 
3. About Penn State Policies. (n.d.). Retrieved from https://policy.psu.edu/about Amazon Business. (n.d.). Retrieved from https://purchasing.psu.edu/amazon-business Ambrose, M., M. Seabright and M. Schminke (2002), "Sabotage in the Workplace: The

4. Role of Organizational Injustice", Organizational Behavior and Human Decision Processes 89(1), pp. 947-965.

5. Angeles, R. and R. Nath (2007), "Business-to-Business E-Procurement: Success Factors and Challenges to Implementation", Supply Chain Management: An International Journal 12(2), pp. 104-115.

6. Appelbaum, S. and B. Shapiro (2006), "Diagnosis and Remedies for Deviant Workplace Behaviors", Journal of American Academy of Business 9(2), pp. 1420.

7. Badenhorst, J. (1994), "Unethical Behavior in Procurement: A Perspective on Causes and Solutions", Journal of Business Ethics 13(9), pp. 739-745

8. Bartolini, A., (2012). CPO Rising 2012: Keeping Score. Boston, NY: Ardent Partners.

9. Bartolini, A. and Browning, W. (2007), Spend Analysis: Working too hard for the Money. Boston, MA: Aberdeen Group.

10. Bartezzaghi, E. (2007), "Quantitative versus qualitative: Putting the question in the right perspective." Journal of Purchasing and Supply Management 13(3), pp. 193-195.

11. BS14 Penn State Purchasing Card. (2016, March 10). Retrieved from https://policy.psu.edu/policies/bs14

12. Chaudhary, P. (2018), "Transaction Cost Analysis at The Pennsylvania State University

13. Purchasing Services Department". The Pennsylvania State University, University Park, Pennsylvania

14. Cousins, P., Lamming, R., Lawson, B., and Squire, B. (2008), "Strategic supply management - principles, theories and practice". Essex, England: Prentice Hall.

15. Cox, A., D. Chicksand and P. Ireland (2005a). "Overcoming Demand Management Problems: The scope for improving Reactive and Proactive Supply Management in the UK Health Service”, Journal of Public Procurement 5(1), pp. $1-22$.

16. Croom, S. and Brandon-Jones, A. (2005), "Key Issues in E-Procurement: Procurement Implementation and Operation in the Public Sector", Journal of Public Procurement 5(3), pp. 367-387.

17. Degnan, C. (2003), the Services Supply Chain Automation Benchmark Report: Strategies for a Buckshot Market. Boston, MA: Aberdeen Group.

18. Dwyer, C.J. (2011), Linking Spend Analytics and Contract Management to Public Procurement. Boston, MA: Aberdeen Group.

19. Dwyer, C.J. and Gupta, A (2008), The E-Procurement Benchmark Report. Boston, MA: Aberdeen Group.

20. FN18 University Approval Authorization Policy. (2014, May 22). Retrieved from https://policy.psu.edu/policies/fn18

21. Gelderman, C., P. Ghijsen and M. Brugman: 2006, "Public Procurement and EU Tendering Directives - Explaining Non-Compliance", International Journal of Public Sector Procurement 19(7), pp. 702-174. 
22. Harland, C., Lamming, R. and Cousins, P. (1999). "Developing the concept of supply strategy", International Journal of Operations \& Production Management 19(7), pp. 650-673.

23. Harris, L. and Ogbonna, E. (2002). "Exploring Service Sabotage: The Antecedents,

24. Types and Consequences of Frontline, Deviant, Antiservice Behaviors". Journal of Service Research 4(3), pp. 163-188.

25. How P-Cards Work. (n.d.). Retrieved from https://www.napcp.org/page/PCardProcess

26. How To Conduct A Spend Analysis in Seven Steps. (2015, June 2). Retrieved from https://www.jaggaer.com/how-to-conduct-a-spend-analysis-in-seven-steps/

27. JPMorgan Chase (2007), Purchasing Card Best Practices for University Procurement

28. Karjalainen, K., (2011), "Estimating the cost effects of purchasing centralization - empirical evidence from framework agreements in the public sector". Journal of Purchasing and Supply Management 17(2), pp. 87-97.

29. Karjalainen, K., Kemppainen, K. and van Raaij, E.M., (2009), "Non-compliant work behavior in purchasing: an exploration of reasons behind maverick buying". Journal of Business Ethics 85, pp. 245-261.

30. Kauppi, K. and van Raaij, E.M., (2014), "Opportunism and Honest Incompetence - Seeking Explanations for Noncompliance in Public Procurement", JPART 25, pp. 953-979.

31. Kulp, S., T. Randall, G. Brandyberry and K. Potts (2006), "Using Organizational Control Mechanisms to Enhance Procurement Efficiency: How GlaxoSmithKline Improved the Effectiveness of E-Procurement", Interfaces 36(3), pp. 209-219.

32. Leenders, M., Johnson, F., Flynn, A. and Fearon, H. (2006). Purchasing and Supply Management. With 50 Supply Chain Cases. New York, NY: McGrawHill Companies.

33. Lonsdale, C. and G. Watson (2005), "The Internal Client Relationship, Demand Management and Value for Money: A Conceptual Model", Journal of Purchasing and Supply Management 11(4), pp. 159-171.

34. Minahan, T.A. and Degnan, C., (2004), Best Practices in Spending Analysis: A Cure for a Corporate Epidemic. Boston, MA: Aberdeen Group.

35. Paulraj, A., Chen, I., and Flynn, J. (2006). "Levels of strategic purchasing: impact on

36. supply integration and performance", Journal of Purchasing and Supply Management 12(3), pp. 107-122.

37. Payment Decision Matrix. (2017, October 12). Retrieved from https://guru.psu.edu/resources/decision-tools/payment-decision-matrix.docx

38. Pikulik, J. (2005), the Purchasing Card Benchmark Report - Best Tactics to Increase Program Growth. Boston, MA: Aberdeen Group.

39. Procedure PC2009 - Penn State Purchasing Card. (2015, April 13). Retrieved from https://guru.psu.edu/procedures/PC2009

40. Roy, S. (2003), "OK You are Now an Approved Supplier - but You Still do not Get Orders: Understanding the Case of the P-Card", Industrial Marketing Management 32(7), pp. 605-613. 
41. Rothkopf, A. and Pibernik, R. (2016), "Maverick buying: Eliminate, participate, leverage?", International Journal of Production Economics 179, pp. 77-89.

42. Toktas Palut, P., Baylav, E., Teoman, S. and Altunbey, M. (2014). "The impact of barriers and benefits of e-procurement on its adoption decision: an empirical analysis", International Journal of Production Economics 158, pp. 77-90.

43. University Policies \& Procedures. (n.d.). Retrieved from https://purchasing.psu.edu/university-policies-procedures

44. Vardi, Y. and Y. Wiener (1996), "Misbehavior in Organizations: A Motivational Framework”, Organization Science 7(2), pp. 151-165.

\section{About Our Authors}

Sureel S. Sheth is a supply chain analytics specialist at CNH Industrial, LLC. He obtained his Bachelor's degree in Mechanical Engineering from Dharamsinh Desai University (Gujarat, India) and his Master's degree in Industrial Engineering with a focus on supply chain management from Penn State University. His research interests surround procurement and spend analysis.

Terry P. Harrison is the Earl P. Strong Professor of Business Administration and Professor of Supply Chain and Information Systems at Penn State University. He is a former President (2012) and Fellow (2014) of INFORMS. His research interests are in the intersection of analytics and supply chain management.

Richard D. Elmore is the Director of Procurement Services at the Pennsylvania State University. In this role, he leads all central purchasing, vendor accounts payable, travel management, supplier diversity, and purchasing card operations at the University and is directly responsible for the execution of over 80,000 purchasing and payments transactions valued at over $\$ 700$ million annually. Before assuming his current position, he served as the Assistant Vice President of Procurement Services at the University of Illinois and prior to that he served in the United States Air Force for twenty-two years holding various operational and strategic Purchasing and Contracting positions at various domestic and worldwide locations. 